\title{
Do Irish adults meet the physical activity recommendations?
}

\author{
T. A. McCrorie ${ }^{1}$, K. L. Rennie ${ }^{2}$, R. Kozarski ${ }^{2}$, B. McNulty ${ }^{3}$, A. Nugent ${ }^{3}$, J. Walton ${ }^{4}$, A. Flynn ${ }^{4}$, \\ M. Gibney ${ }^{3}$ and M. B. E. Livingstone ${ }^{1}$ \\ ${ }^{1}$ Northern Ireland Centre for Food and Health (NICHE), University of Ulster, Coleraine, BT52 ISA, UK, \\ ${ }^{2}$ Health and Human Sciences Research Institute, University of Hertfordshire, AL10 9AB, UK, \\ ${ }^{3}$ UCD Institute of Food and Health, University College Dublin, Belfield, Dublin 4 and ${ }^{4}$ School of Food and Nutritional \\ Sciences, University College Cork, Cork, Republic of Ireland
}

Current physical activity recommendations (PAR) for Irish adults are to achieve a minimum of 150 mins/wk of at least moderate intensity physical activity (MPA) or 75 mins/wk of vigorous physical activity (VPA) ${ }^{(1)}$. Typically PA levels which are determined using activity questionnaires are prone to misreporting and are inconsistent in validity and reliability ${ }^{(2)}$. However, data collected using accelerometers provide an objective measure of PA, as well as information on frequency, intensity and time spent in PA. The aim of this study is to describe PA patterns in Irish adults.

A nationally representative group of Irish adults ${ }^{(3)}(n=1111,18-85$ yrs) wore a uni-axial accelerometer (Actigraph, GTM1) for 4 consecutive days. Time spent in moderate and vigorous PA (MVPA) was determined using cut-offs ${ }^{(4)}$ and was normalised to give weekly estimates of PA. Anthropometric measures of weight and height were also performed and BMI $\left(\mathrm{kg} / \mathrm{m}^{2}\right)$ was calculated. Fat mass $(\mathrm{kg})$ determined by bio-electrical impedance, was adjusted for height (fat mass index FMI, $\mathrm{kg} / \mathrm{m}^{2}$ ) and expressed relative to total body weight $(\%)$.

Removal of non-wear times resulted in complete accelerometry data ( $\geq 600 \mathrm{mins} / \mathrm{d}$ for 2 to 4 days) for $n=849$ subjects. There were no significant differences between those with complete accelerometer and those without complete data (weight, age or BMI $P>0.05$ ) apart from height $(1.68 \mathrm{~m}$ vs. $1.7 P=0.045)$.

\begin{tabular}{|c|c|c|c|c|c|c|c|c|c|c|c|c|}
\hline & \multicolumn{6}{|c|}{ Males } & \multicolumn{6}{|c|}{ Females } \\
\hline & \multicolumn{3}{|c|}{ Below PAR (n 33) } & \multicolumn{3}{|c|}{ Meeting PAR ( $n$ 358) } & \multicolumn{3}{|c|}{ Below PAR $(n 68)$} & \multicolumn{3}{|c|}{ Meeting PAR ( $n$ 390) } \\
\hline & \multirow[b]{2}{*}{ Median } & \multicolumn{2}{|c|}{ Percentiles } & \multirow[b]{2}{*}{ Median } & \multicolumn{2}{|c|}{ Percentiles } & \multirow[b]{2}{*}{ Median } & \multicolumn{2}{|c|}{ Percentiles } & \multirow[b]{2}{*}{ Median } & \multicolumn{2}{|c|}{ Percentiles } \\
\hline & & 25 th & $\overline{75 \text { th }}$ & & 25 th & $\overline{75 \text { th }}$ & & 25 th & $\overline{75 \text { th }}$ & & 25 th & 75 th \\
\hline Weight (kg) & 87.6 & 76.3 & 99.4 & 84.7 & 76.3 & 93.2 & 70.1 & 64.0 & 81.6 & $67.5^{* *}$ & 60.0 & 75.5 \\
\hline Height $(\mathrm{m})$ & 1.7 & 1.7 & 1.8 & 1.8 & 1.7 & 1.8 & 1.6 & 1.6 & 1.7 & 1.6 & 1.6 & 1.7 \\
\hline BMI $\left(\mathrm{kg} / \mathrm{m}^{2}\right)$ & 29.4 & 26.5 & 31.8 & $27.4^{*}$ & 24.7 & 29.9 & 27.1 & 24.2 & 31.2 & $25.2 * *$ & 22.5 & 27.9 \\
\hline Fat mass $\%$ & 27.2 & 22.6 & 32.6 & $24.1 * *$ & 19.2 & 28.2 & 37.6 & 31.9 & 41.3 & $33.9^{* *}$ & 28.7 & 38.8 \\
\hline Fat mass (kg) & 24.8 & 18.9 & 30.9 & $20.4 * *$ & 15.2 & 25.9 & 26.0 & 20.2 & 32.6 & $22.8^{* *}$ & 17.1 & 28.9 \\
\hline FMI $\left(\mathrm{kg} / \mathrm{m}^{2}\right)$ & 8.1 & 5.9 & 10.3 & $6.7 * *$ & 4.7 & 8.4 & 10.0 & 7.8 & 12.3 & $8.5^{* *}$ & 6.5 & 10.8 \\
\hline MPVA Mins/wk & 120.2 & 102.6 & 141.4 & $393.8 * *$ & 280.9 & 556.3 & 102.7 & 72.7 & 140.7 & $331.6^{* *}$ & 245.4 & 467.2 \\
\hline
\end{tabular}

BMI, body mass index; FMI, fat mass index; MVPA, moderate and vigorous physical activity; PAR, physical activity recommendation. Median values were significantly

different from those Below PAR (Mann Whitney U test) $* P<0.05, * * P<0.01$.

Approximately $88 \%$ of Irish males and females met the weekly PAR. Those who met the PAR had significantly lower BMI and fat mass $(\%, \mathrm{~kg})$ and FMI. Further analysis of these data will allow for more complete understanding of the relationship between body composition and PA in Irish adults.

This study was funded by the Irish Department of Agriculture, Fisheries and Food under the Food for Health Research Initiative (2007-2012). Ethical approval was obtained from the University College Cork Clinical Research Ethics Committee of the Cork Teaching Hospitals and was conducted according to the guidelines laid down in the Declaration of Helsinki.

1. Department of Health and Children, Health Service Executive Ireland (2009).

2. Livingstone et al. (2003) Proc Nut Soc.

3. Irish Universities Nutrition Alliance (2011) www.iuna.net

4. Freedson et al. (1998) Med Sci Sport Exer. 